\title{
Paracetamol-induced ductal closure in a 5-month-old infant
}

Received: 28 June 2014; Accepted: 3 July 2014; First published online: 4 August 2014

To the Editor,

Recently, we cared for a 5-month-old baby boy born at 28 weeks gestation with a $1.9-\mathrm{mm}$ patent ductus arteriosus (Fig 1). The parents were counselled regarding the plan for percutaneous device closure and asked to return 2 weeks later. Surprisingly, on repeat echocardiogram, the ductus arteriosus had closed.

As spontaneous ductal closure is unusual past the newborn period, we questioned the parents about the events in the preceding 2 weeks. The parents reported administering paracetamol $12 \mathrm{mg} / \mathrm{kg} /$ dose twice daily for 4 days because of fussiness and nasal congestion. In premature infants during the newborn period, indomethacin or ibuprofen are first-line agents utilised for ductal closure. In patients with contraindications to non-steroidal anti-inflammatory drugs, paracetamol at $15 \mathrm{mg} / \mathrm{kg} /$ dose every 6 hours for 48 hours has been used effectively as a second-line agent. ${ }^{1,2}$ Previous authors have suggested that paracetamol works by acting at the peroxidase segment of prostaglandin synthetase and inhibits activity. ${ }^{3}$

To the best of our knowledge, our case is the first reported case of ductal closure associated with paracetamol outside of the newborn period. Further studies are needed to elucidate the role of paracetamol for ductal closure beyond the neonatal period.

\section{Acknowledgements}

C.H. drafted the initial manuscript, conducted the literature search, revised subsequent versions of the manuscript, and approved the final manuscript as submitted. G.G. performed the literature search, revised subsequent versions of the manuscript, and approved the final manuscript as submitted. M.E. revised subsequent versions of the manuscript and approved the final manuscript as submitted. M.U. revised subsequent versions of the manuscript and approved the final manuscript as submitted.

Correspondence to: C. H. Ho, MD, Keck School of Medicine, Los Angeles County + University of Southern California Medical Center, 2020 Zonal Avenue, IRD Room 109 Los Angeles, CA 90033, United States of America. Tel: 323226 3691; Fax: 323226 5692; E-mail: cynho@usc.edu

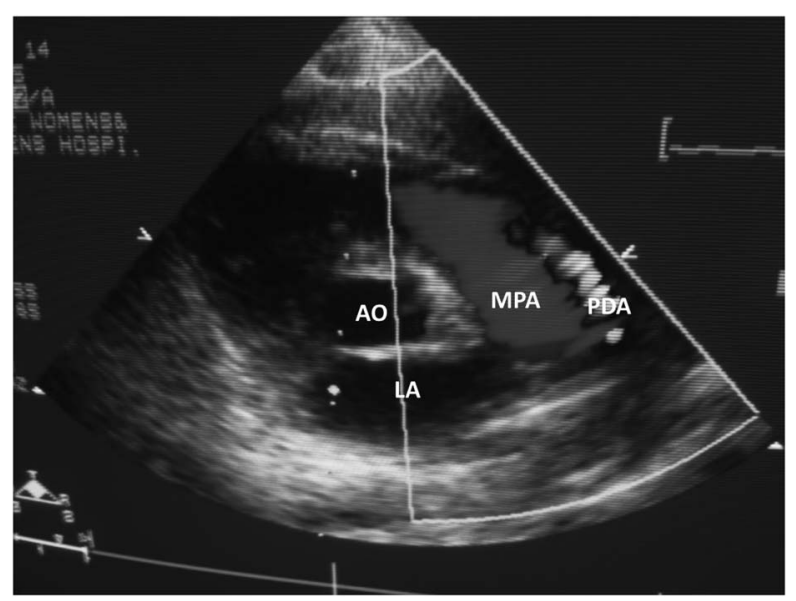

Figure 1.

Transthoracic echocardiogram (parasternal short-axis view) at 51 weeks gestational age showing a patent ductus arteriosus and mildly dilated $L A$ and left ventricle. $A O=$ aorta; $M P A=$ main pulmonary artery; $L A=$ left atrium.

\section{Financial Support}

This research received no specific grant from any funding agency, commercial, or not-for-profit sectors.

\section{Conflicts of Interest}

None.

\section{Ethical Standards}

The manuscript is original and has not been accepted or published elsewhere.

Cyntbia H. Ho

Department of Pediatrics, Keck School of Medicine Los Angeles County + University of Southern California Medical Center, Los Angeles, California United States of America

Department of Internal Medicine, Keck School of Medicine, Los Angeles County + University of Southern California Medical Center, Los Angeles, California United States of America 
Gracie Galiza

Department of Pediatrics, Keck School of Medicine

Los Angeles County + University of Southern California Medical Center, Los Angeles, California United States of America

Mabmood Ebrabimi

Department of Pediatrics, Keck School of Medicine Los Angeles County + University of Southern California Medical Center, Los Angeles, California United States of America

Division of Cardiology, Keck School of Medicine Los Angeles County + University of Southern California Medical Center, Los Angeles, California United States of America

Merujan Y. Uzunyan Department of Pediatrics, Keck School of Medicine Los Angeles County + University of Southern California
Medical Center, Los Angeles, California United States of America

Division of Cardiology, Keck School of Medicine Los Angeles County + University of Southern California Medical Center, Los Angeles, California United States of America

\section{References}

1. Allegaert K, Anderson B, Simons S, van Overmeire B. Paracetamol to induce ductus arteriosus closure: is it valid? Arch Dis Child 2013; 98: 462-466.

2. Hammerman C, Bin-Nun A, Markovitch E, Schimmel MS, Kaplan M, Fink D. Ductal closure with paracetamol: a surprising new approach to patent ductus arteriosus treatment. Pediatrics 2011; 128: e1618-e1621.

3. Lucas R, Warner TD, Vojnovic I, Mitchell JA. Cellular mechanisms of acetaminophen: role of cyclo-oxygenase. FASEB J 2005; 19: 635-637. 